\title{
Uma análise da expansão territorial urbana das cidades médias a partir da escala geográfica: o exemplo de Presidente Prudente/SP
}

\author{
An analysis of the urban territorial expansion of middle cities from the geographical scale: The \\ example of Presidente Prudente/SP
}

\section{Historial del artículo \\ Recibido: \\ 25 de mayo de 2021}

Revisado

22 de junio de 2021

Aceptado:

22 de junio de 2021

\section{Felipe César Augusto Silgueiro Dos Santos ${ }^{\mathrm{a}}$}

a Faculdade de Ciências e Tecnologia, Universidade Estadual Paulista - Departamento de Geografia - FCT/UNESP - Câmpus de Presidente Prudente/SP. Correo electrónico: felipe.cesar@unesp.br. ORCID: https://orcid.org/0000-0002-4073-0820

\section{Palavras-chave}

Cidades médias, escala geográfica, espaço-tempo, Presidente Prudente/SP, política habitacional

\section{Keywords}

Geographical scale, housing policy, medium-sized cities, Presidente Prudente / SP, space-time

\begin{abstract}
Resumo
As escalas geográficas possuem importância na Geografia por permitirem uma análise hierárquica dos fatos mediante uma visão crítica de caráter social e político. Frente a uma intensa modificação espacial realizada pelo sistema capitalista, elas surgem como possibilidade de entendimento dessas relações contraditórias estabelecidas pelo capital. Para constatar tal reflexão, podemos nos utilizar da implantação de políticas públicas em cidades médias, que possuem uma importância significativa na produção de seu espaço urbano além de possibilitar uma análise espaço-temporal para compreender como essas políticas verticalizadas possuem influência direta na produção e modificação desse espaço, utilizando da ideia de análise escalar. É o que mostraremos neste artigo ao analisar Presidente Prudente/SP, com sua produção habitacional que produz o espaço urbano, alocando as citadinas e citadinos nos mais variados espaços. Mediante uma análise de seu contexto habitacional em nível histórico e de uma representação visual dos dados coletados, podemos constatar que é possível produzir cidades a partir de decisões verticais mediante políticas públicas, reveladas pela análise escalar geográfica.
\end{abstract}

\section{Palabras clave}

Ciudades medianas, escala geográfica, Presidente Prudente / SP, política de vivienda, tempo espacial

\begin{abstract}
Geographical scales are important in Geography as they allow a hierarchical analysis of facts through a critical view of a social and political nature. Faced with an intense spatial modification carried out by the capitalist system, they appear as a possibility of understanding these contradictory relationships established by capital. To verify this reflection, we can use the implementation of public policies in medium-sized cities, which have a significant importance in the production of their urban space, in addition to enabling a spatio-temporal analysis to understand how these vertical policies have a direct influence on the production and modification of this space, using the idea of scalar analysis. This is what we will show in this article when analyzing Presidente Prudente/SP, with its housing production that produces urban space, allocating city and city dwellers in the most varied spaces. Through an analysis of their housing context at a historical level and a visual representation of the collected data, we can see that it is possible to produce cities from vertical decisions through public policies, revealed by the geographic scalar analysis.
\end{abstract}

\footnotetext{
Resumen

Las escalas geográficas son importantes en Geografía ya que permiten un análisis jerárquico de los hechos a través de una mirada crítica de carácter social y político. Frente a una intensa modificación espacial llevada a cabo por el sistema capitalista, aparecen como una posibilidad de comprender estas relaciones contradictorias que establece el capital. Para verificar esta reflexión, podemos utilizar la implementación de políticas públicas en ciudades medianas, las cuales tienen una importancia significativa en la producción de su espacio urbano, además de posibilitar un análisis espacio-temporal para entender cómo estas políticas verticales tienen un impacto directo. Influir en la producción y modificación de este espacio, utilizando la idea de análisis escalar. Esto es lo que mostraremos en este artículo al analizar Presidente Prudente / SP, con su producción habitacional que produce espacio urbano, ubicando ciudad y habitantes de la ciudad en los más variados espacios. A través de un análisis de su contexto habitacional a nivel histórico y una representación visual de los datos recolectados, podemos ver que es posible producir ciudades a partir de decisiones verticales a través de políticas públicas, reveladas por el análisis escalar geográfico.
} 


\section{Introdução}

Utilizar de novas ferramentas para realizar a compreensão das dinâmicas existentes no espaço-tempo é um mecanismo de entendimento das modificações espaciais vigentes. Pensar a escala geográfica como um desses novos instrumentos é uma alternativa viável, devido à capacidade de amplitude nas reflexões que ela nos permite.

Em um momento em que temos uma redução sistemática do espaço-tempo para a realização das atividades cotidianas, a escala geográfica surge como possibilidade de entendimento de um universo de processos e ações que ocorrem e que estão elencados para a formação do pensamento atual.

Mas como tal fenômeno pode colaborar nas análises referente as cidades, sendo que ainda temos grandes problemas relacionados ao planejamento urbano, as políticas públicas, ao acesso a moradia, qualidade dessas, indisponibilidade de serviços básicos como postos de saúde, escolas etc.?

Ao refletir sobre a dinâmica urbana mediante as ações do planejamento urbano, por exemplo, é possível apontar que a análise a partir das escalas geográficas permite identificar questões como a segregação socioespacial, a fragmentação socioespacial, a financeirização imobiliária etc., que se originam a partir das mais variadas relações estabelecidas pela produção do espaço urbano oriunda de uma política pública.

Desse modo, partimos do pressuposto de que a escala geográfica atua como uma forma de compreensão da dinamização que ocorre nos processos do espaço-tempo das dinâmicas sociais e políticas. Iremos verificar tal situação ao analisar Presidente Prudente/SP com sua produção habitacional que produz o espaço urbano, alocando as citadinas e citadinos nos mais variados espaços.

Esta cidade média tem se figurado como uma das beneficiadas pelas políticas públicas dos últimos 10 anos, principalmente as que estão relacionadas a produção habitacional. Consultando sua expansão urbana a partir de uma reflexão espaço-temporal, é notório que a cidade se dinamizou em seu formato e no seu tamanho populacional, que cresce significativamente, principalmente por conta de sua expansão territorial urbana mediante a produção habitacional.

Assim sendo, iniciaremos nosso texto fazendo uma breve explanação sobre a escala geográfica e suas relações com a questão urbana. Tentaremos simplificar o debate referente a ela para que possa ser compreendida em todas as suas faces, visando deixar o caminho aberto para outras possibilidades de discussão.

Posteriormente, faremos um debate sobre o espaço-tempo e a sua "compressão" frente à imposição do sistema capitalista de reduzir o tempo e modificar o espaço.

Como forma de exemplificar nossas reflexões utilizaremos a influência que a política habitacional teve em uma cidade média, para compreender como a relação escalar está diretamente ligada à análise espaço-tempo, isso verificado nas ações que culminaram com sua implantação, fazendo um resgate a partir da trajetória habitacional da cidade utilizada para o estudo.

\section{O debate referente à escala geográfica: breves apontamentos}

O debate sobre escalas na Geografia vem ganhando importância nos últimos anos, devido ao avanço que as pesquisas têm alcançado, especificamente nas análises referentes à produção do espaço.

Compreendemos que há uma variedade de frentes relacionadas à escala (geográfica, cartográfica, escala operacional como representação, escala topológica, escala topográfica, escala do império e escala ação) conforme Santos e Silva (2014) já destacaram. Porém, optamos por abordar a escala geográfica, que ainda carece de um aprofundamento maior de suas análises, que em nosso entendimento, melhor debate a questão doespaço-tempo.

O espaço tem se tornado cada vez mais multifacetado devido à intensa modificação que se visualiza, já que ele tem sido reduzido e transformado cada vez mais, e em um curto tempo. Concordamos com Carlos (2009) quando a autora destaca que:

O espaço como possibilidade de compreensão do mundo contemporâneo - do pensamento capaz de se apropriar do mundo (de sua explicação) na construção de um edifício teórico capaz de sustentar ou fundamentar o conhecimento do mundo social pela Geografia ou através dela - impõe a necessidade de pensar a potência da noção de produção do espaço para o desvendamento do mundo moderno. (p. 78)

Por sua vez, o espaço torna-se complexo frente a essa gama de novas realidades existentes, que não permitem o entendimento de forma rasa, onde não se realiza o contexto fundamental de entendimento das novas vivências, em meio a um mundo pós-moderno que espanta pela sua intensa 
alteração, pela velocidade de suas novas demonstrações e inserções no cotidiano das pessoas.

Essas modificações advêm da influência que o sistema capitalista possui na elaboração e no estabelecimento das relações, conforme Brenner (2013, p. 201) destaca:

Evidentemente, as ciências sociais há muito tempo continham premissas acerca da constituição escalar dos processos político-econômicos - desde a acumulação de capital e a regulação estatal até a urbanização e a mobilização sociopolítica. Porém, esses avanços interdisciplinares mais recentes indicam que a questão da escala está sendo, hoje, confrontada com reflexividade metodológica sem precedentes, em um contexto de debates mais amplos sobre a reestruturação capitalista mundial.

Ao expor esse pensamento, o autor deixa claro que a análise escalar passa por um processo de intensa variação devido à característica contraditória que o sistema capitalista possui, já que busca sempre a rentabilidade em virtude da produção massiva.

Quando focamos a questão urbana temos o entendimento de que a produção do espaço urbano é fortemente influenciada pelos seus produtores, assim como pelos agentes sociais, partindo tanto da visão mais amplificada, como de um ponto mais específico, como porexemplo, a moradia, desde que sejam respeitadas a visões teórico- metodológicas de ambos (Santos e Silva, 2014).

Quando tratamos da questão moradia, epartindo para uma visão mais próxima do citadino, na ideia de sentimento de "casa", podemos nos utilizar das ideias de Smith (2000, p. 147):

Lugar de reprodução pessoal e familiar, a casa é uma localização física e talvez uma estrutura permanente ou temporária. Os atos rotineiros de reprodução social - comer, dormir, fazer sexo, limpar, criar filhos - estão baseados (mas não são exclusivamente praticados) no lar e em torno dele.

[...] Internamente, a diferenciação da casa pode variar de uma dicotomia simples dentro/fora até uma divisão mais elaborada; ela representa uma espacialização de diferentes experiências, atividades e funções sociais, ou combinações delas; e é mobiliada de acordo com essa espacialização.

Pensar por esse ponto nos leva a destacar que, ele funciona como um grande destaque para o estabelecimento das relações sociais, concentrando-se em uma escala direcionada de sua organização, podendo-se verificar que essas pequenas relações possuem grande influência como em questões de gênero, que o mesmo autor traz em seu texto.

Quando partirmos do pressuposto da casa, queremos compreender um fragmento diante de uma dinâmica maior inserida no debate escalar; a questão urbana. Apoiamonos em Brenner (2013), quando o autor destaca que:

[...] a escala urbana opera como um nó local no interior dos circuitos globalmente organizados de acumulação de capital, enquanto a escala global é, por sua vez, constituída mediante redes de cidades e cidades- regiões interconectadas.

[...] Dessa perspectiva, o urbano não é apenas um nível encaixado em hierarquias político-econômicas supraurbanas, mas também é o produto de densas redes interescalares vinculando lugares espalhados por todo o sistema global. (pp. 205-206)

Ao refletir sobre a visão escalar referente ao urbano o autor deixa claro que o constructo relacionado à observação da análise pelas escalas referente à questão urbana é pautado na interligação, nas conexões existentes entre as cidades.

Desse modo, quando realizamos a análise escalar sobre a casa, por exemplo, temos uma gama de informações que é permitida perante a infinidade de relações ali existentes, conforme Smith (2000) detalhou. Logo, a visão escalar contribui para entender a visão mais específica até uma compreensão em um âmbito maior.

Melo (2003) apresenta o que seria a escala, a partir de sua influência nas relações sociais e políticas:

As escalas são dimensões de fenômenos que se manifestam como exteriorização de conflitos inerentes a relações sociais que conformam o instituído, seja ele o corpo, a família, a cidade, a região, o país, o continente ou o mundo. Essas escalas são, portanto, escalas de conflitos políticos. As relações entre elas também são conflituosas, pois os discursos hegemônicos conformadores das escalas ocultam lacunas, vazios que se explicitam nas negações inter-escalares. Se um fato impressiona o mundo capitalista de tradição judaicocristã, os atores políticos responsáveis imediatos por ele, ao mesmo tempo em que expõem contradições do global, são desnudados pelo global. (p. 38)

Ou seja, desde uma escala mais particular, como a do corpo, podemos ter manifestações que influenciam diretamente 
no estabelecimento das relações sociais e políticas, denotando que, com a análise a partir das escalas, há a manutenção de uma efetividade com relação à validade das informações, já que uma observação escalar compreende uma amplitude de dimensões.

Assim sendo, a escala geográfica surge como ponto possível para a compreensão dessas novas realidades, especificamente daquelas voltadas à "compressão" do espaço-tempo pelo sistema capitalista, que demanda um entendimento não só do que está posto, mas, de todo o contexto que está criado e que se insere nas relações sociais e políticas vigentes.

O espaço-tempo: uma visão crítica a partir de sua "compressão"

Uma crítica que tem sido destacada nos momentos atuais é a intensa redução do espaço e do tempo para adequar-se às imposições do sistema capitalista, que emerge em um avanço em vários âmbitos, como a tecnologia, mas que compromete o cotidiano das pessoas, com um espaço cada vez mais transformado e um tempo cada vez mais curto.

Tal ponto advém da necessidade de o sistema capitalista reproduzir-se em uma constante que possa ser rápida, já que a visão do lucro é pensada para ocorrer de forma tão veloz quanto a troca dessas informações.

Essa dinamicidade estabelecida a partir da velocidade das trocas de informações é fundamental para o que capital possa se reproduzir e se estabelecer enquanto modelo econômico, o que é refletido nas decisões políticas e sociais que são tomadas para que o sistema continue vivo e ativo.

Carlos (2009) destaca a importância que a Geografia possui frente a essas novas realidades do mundo contemporâneo:

A Geografia, ao apontar a inexorabilidade da relação espaço-tempo, aponta uma perspectiva nova para a elucidação do período atual. Poderíamos assim argumentar que a pós-modernidade referir-se-ia a uma radical mudança espaço temporal e não apenas temporal. (p. 81)

A autora busca apontar que a Geografia atua como ferramenta de entendimento desse mundo pós-moderno, baseado na modificação intensa do espaço-tempo, onde a disciplina geográfica atua como modelo de compreensão dessas relações espaços-temporais.
Quando apontamos que o tempo é encurtado para dar dinamismo na troca de informação, entendemos que há, pelo atual momento do moderno e do pós-moderno, a necessidade de contabilizar e pensar no tempo, conforme Elias (1998) destaca:

Os relógios não medem o tempo? Se eles permitem medir alguma coisa, não é o tempo invisível, mas algo perfeitamente passível de ser captado, como a duração de um dia de trabalho ou de um eclipse lunar, ou a velocidade de um corredor na prova dos cem metros. Os relógios são processos físicos que a sociedade padronizou, decompondo-os em seqüênciasmodelo de recorrência regular, como as horas ou os minutos. (p. 7)

Ao pensar desse modo, em calcular o tempo gasto, o autor busca deixar claro que é possível entender a necessidade atual de se regularizar o seu tempo de ação e de vivência para encaixar-se na realidade dinâmica contemporânea, em que o relógio deve se tornar um aliado, frente à constante mudança ocorrida no cotidiano.

Logo, se contabiliza cada movimento e cada passo para que se encaixe em uma dinâmica de atividades e que possa ser rentável, respeitando o modelo econômico que é adotado, o que é possível verificar e compreender nas políticas públicas, que são pensadas para seguir o mesmo movimento.

Harvey (1992) nos traz um exemplo de como o dinheiro modifica uma dinâmica espaço-temporal completa:

Em primeiro lugar, a progressiva monetização das relações na vida social transforma as qualidades do tempo e do espaço. A definição de um "tempo e um lugar para tudo" muda necessariamente, formando uma nova estrutura de promoção de novos tipos de relações sociais. Os mercadores medievais, por exemplo, ao construírem uma melhor medida de tempo "para a conduta organizada dos negócios", promoveram uma "modificação fundamental na medida do tempo que representou, na realidade, uma mudança do próprio tempo." Simbolizados pelos negócios e sinos que chamavam os trabalhadores para trabalhar e os mercadores para comerciar, afastados dos ritmos "naturais" da vida agrária e divorciados das significações religiosas, os mercadores e mestres criaram uma "nova rede cronológica" em que a vida cotidiana foi aprisionada. A nova definição de trabalho não foi contestada pela autoridade religiosa e nem pelos trabalhadores convocados a aceitar as novas regras da disciplina temporal. (p. 208) 


\section{PORCENTAGEM DA POPULAÇĀO COM ACESSO À INTERNET PELO MUNDO}

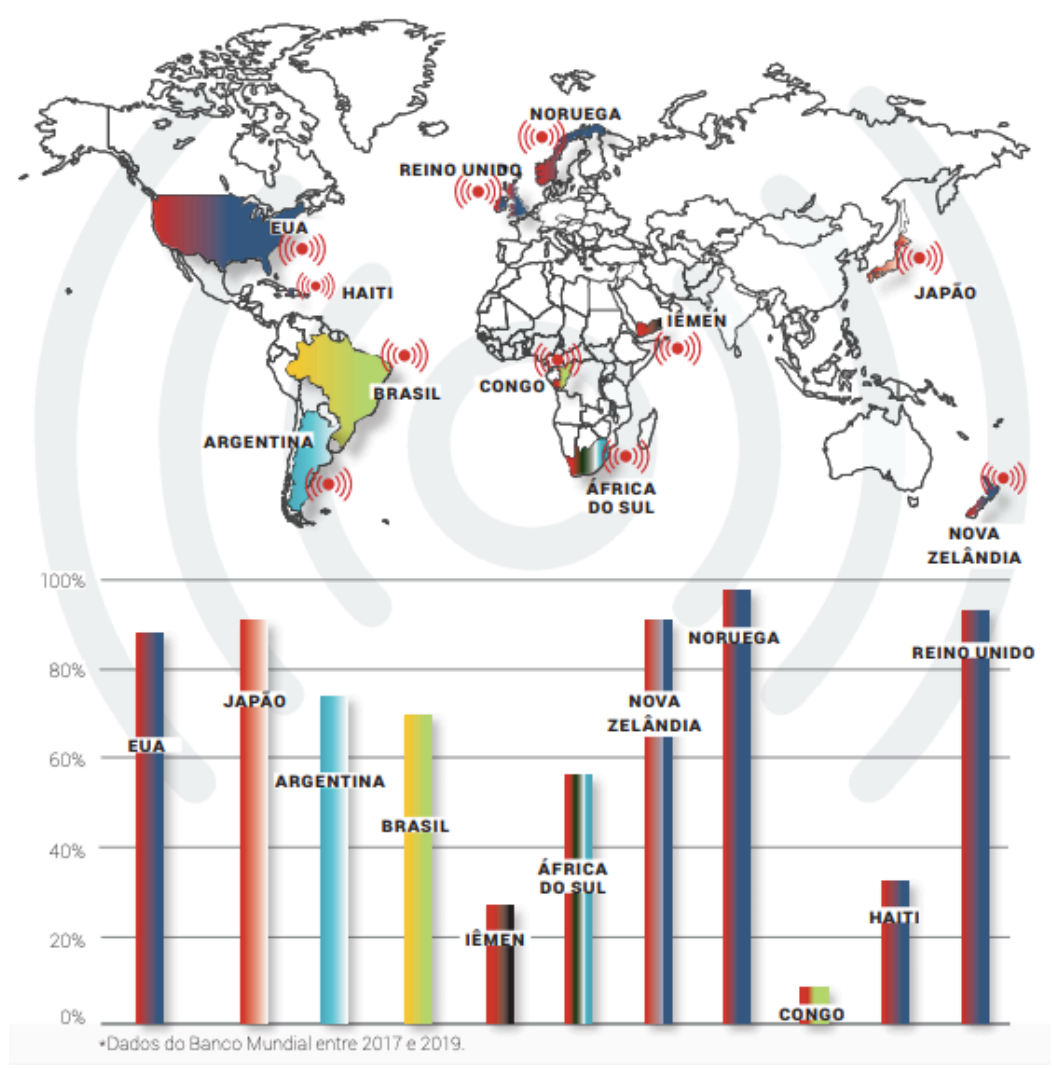

Figura 1. Porcentagem da população com acesso à Internet pelo mundo (2017 - 2019). Fonte: Cristianini (2020).

Quando o autor faz essa reflexão, trazendo como exemplo os mercadores europeus, suas ideias nos trazem à atualidade, onde os horários estipulados pelas empresas regem o dia a dia dos trabalhadores, tendo uma modificação intensa do espaço-tempo de cada um.

Desse modo, pensar na diminuição do tempo mediante a atuação do sistema capitalista, no s indica refletir que as fronteiras espaciais estão cada vez mais reduzidas e que o mundo diminui a cada ano devido à velocidade que o acesso pode ofertar (Harvey, 1992).

A figura 1 ilustra como o mundo se tornou mais conectado com o advento da Internet.

A conectividade oriunda da Internet permite que se faça acessos a várias informações existentes no mundo com um simples clique no computador ou celular, demonstrando que estamos cada vez mais ligados por teias digitais que nos fornecem notícias, músicas, imagens etc. em um curto espaço de tempo.
Harvey (1992) destaca que:

À medida que o espaço para encolher numa "aldeia global" de telecomunicações e numa "espaçonave terra" de interdependências ecológicas e econômicas - para usar apenas duas imagens conhecidas e corriqueiras -, e que os horizontes temporais se reduzem a um ponto em que só existe o presente (o mundo do esquizofrênico), temos de aprender a lidar com um avassalador sentido de compressão dos nossos mundos espacial e temporal. (p. 219).

Quanto cada vez mais o espaço é comprimido em prol de um tempo que se encurta a todo o momento, criamos a possibilidade de deixarmos as realidades descartáveis e sem uma reflexão coerente, o que denota o esquecimento frente às vivências de cada pessoa, algo que para o sistema capitalista é viável. 
Sendo esse sistema baseado no lucro, quando temos uma diminuição do espaço em prol de uma velocidade do tempo, verifica-se uma necessidade de criar um sentimento de rapidez na produção, no lazer e nas relações sociais devido à contagem do relógio que comprime o espaço-tempo a cada instante.

Este sistema apontado atinge, por exemplo, as políticas habitacionais com relação a financeirização do solo, já que quando se precifica um pequeno pedaço de terra para que ele seja rentabilizado, ele está inserido numa estrutura econômica maior, que irá regulamentar a localização dos que possuem capital significativo para pagar por aquele local (Encinas et al., 2019).

Isso dentro de um modelo neoliberal ligado a produção do espaço urbano, onde há a necessidade de venda para que continue presente em uma economia pautada no espaço privado. Essa questão contribui para as lógicas de venda rápida de habitações para que o sistema continue ativo e gerando lucro para as incorporadoras (Jimenes et al., 2018)

Desse modo, é possível destacarmos que há um encolhimento do espaço-tempo em prol do sistema capitalista de produção, que reduz as relações mediante a necessidade de entender que o tempo é fluido e seu controle denota a importância da amplitude no acesso à informação e no encurtamento da localização dos lugares.

Essa nova visão distorce o entendimento das realidades devido ao fato de que não há uma reflexão coerente em vista da necessidade de obter resultados prontos em um curto tempo, o que compromete a análise espacial adequada. Assim, destacamos que novas frentes podem surgir como pontos de debate para essas novas realidades, como, no caso, o entendimento da escala geográfica para os apontamentos frente à “compressão" do espaço- tempo.

As políticas públicas em uma visão escalar: a política habitacional em Presidente Prudente/SP no espaço- tempo

A expansão territorial urbana das cidades brasileiras é uma realidade presente há muito tempo. Como as cidades precisam acompanhar o crescimento do quantitativo populacional, é fundamental que as medidas do planejamento urbano acompanhem essa realidade de expansão, principalmente para criar uma regulação das medidas, que nem sempre poderá respeitar o que é estabelecido pelas leis, demandando um cuidado com o que é verificado (Lima et al., 2019).

A análise espaço - temporal permite elencar uma série de reflexões acerca da dinâmica existente nas relações sociais e políticas. Como exemplo de tal ideia, a partir de um estudo no espaço-tempo das políticas públicas em um âmbito escalar, podemos compreender como algumas ações verticalizadas possuem influência direta na expansão das cidades.

A atuação das políticas públicas nas cidades é fundamental para o estabelecimento do desenvolvimento social, já que através delas há a garantia de moradia, renda, saúde, educação, além de acesso a outros benefícios, como ao ensino superior, entre outras garantias fundamentais.

Consideramos esta visão por compreender que, no caso do Brasil, sua expansão territorial permite uma variedade de realidades estabelecidas de acordo com o tempo, que modificam intensamente o espaço vivido, que será dotado das relações sociais e políticas particulares dessa amplitude, o que demandaumcuidado dosagentes públicos na elaboração de políticas sociais (Guimarães, 2003).

E essas políticas devem abarcar a expansão difusa da urbanização brasileira, que está alocada em lógicas não tão claras, mas que devem ser refletidas utilizando os mais variados meios científicos, principalmente no que se refere a implantação de políticas públicas de grande impacto nessas cidades (Bernardini, 2018).

Como exemplo recente, tivemos a implantação de um programa habitacional, em nível nacional, que correspondeu a uma tentativa de atuar no déficit de moradias populares no Brasil, depois de anos da última política de habitação voltada a uma classe de renda mais baixa - o Programa "Minha Casa, Minha Vida" (PMCMV).

Instituído no ano de 2009, o PMCMV foi lançado no segundo governo de Luís Inácio Lula da Silva, e possuía metas de produção habitacional que chegavam a 1 milhão de habitações sociais como forma de conter o déficit habitacional brasileiro.

Além de conter esse déficit, a política do PMCMV também visava corresponder às necessidades do mercado, já que, trabalharia com a construção civil, que necessita de uma demanda de trabalhadores muito grande, e nem todos com uma especialização, além de injetar dinheiro nas construtoras e no setor imobiliário (Amore, 2015).

Como a política do PMCMV visava atingir o país inteiro, era necessário que fossem levadas em consideração as particularidades de cada estado da federação, que não possui igualdade de desenvolvimento social, no setor econômico ou até mesmo no que tange às políticas sociais, 
Tabla 1

Produção habitacional em Presidente Prudente/SP por décadas (1960 - 2000).

\begin{tabular}{ll}
\hline 1960 & $\begin{array}{l}\text { Temos a implantação do Banco Nacional de Habitação (BNH), no ano de 1964, que terá forte atuação em } \\
\text { Presidente Prudente/SP, a partir de 1965, até a sua dissolução em 1985. }\end{array}$ \\
\hline 1970 - 1980 & $\begin{array}{l}\text { Temos a entrega de dez conjuntos habitacionais totalizando 4.766 habitações sociais, que possuíam } \\
\text { investimentos do BNH e recursos do governo do Estado de São Paulo. BNH dissolve-se em 1985. }\end{array}$ \\
\hline 1990 & $\begin{array}{l}\text { Com o fim do BNH houve um grande recuo com relação à produção de habitação social em Presidente } \\
\text { Prudente/SP. Como forma de solução, a prefeitura incluiu cerca de mais de } 772 \text { famílias em um programa } \\
\text { chamado "Programa de Desfavelamento de Lotes Urbanizados" e outro chamado "Concessão do Direito Real } \\
\text { de Uso". }\end{array}$ \\
\hline Anos 2000 & $\begin{array}{l}\text { Retomada da produção habitacional através do Programa "Minha Casa, Minha Vida" do ano de 2009. Em } \\
\text { Presidente Prudente temos a implantação de cinco conjuntos habitacionais totalizando 3.464 habitações social. }\end{array}$ \\
\hline
\end{tabular}

Fonte: 0 autor (2021).

como saneamento básico, segurança. Tal ponto pode ser observado, quando fazemos uma relação direta com uma cidade média do interior do Estado de São Paulo, contemplada com as políticas habitacionais do PMCMV.

Presidente Prudente/SP, localizada na porção oeste do Estado de São Paulo, foi elevada a município em 14 de setembro de 1917, mediante a união das glebas de Francisco de Paula Goulart e José Soares Marcondes. No ano de 2020, de acordo com a plataforma IBGE/CIDADES ${ }^{1}$, conta com 230.371 habitantes, apresentando uma configuração mais avançada desde sua formação e onde, pela espacialização das políticas habitacionais, pôde encontrar uma forma de concentrar boa parte dessa população.

A tabela 1 sintetiza o histórico habitacional de Presidente Prudente/SP.

É possível observar que no período dos anos 1960 até o início dos anos 2000, Presidente Prudente/SP teve uma produção habitacional acima das 10.000 habitações sociais. Nas décadas de 1970 - 1980 houve a entrega de 4.766 habitações espacializadas em dez conjuntos habitacionais, onde podemos perceber que houve um impacto significativo da produção de habitação social na cidade, caracterizando uma influência massiva da produção do espaço urbano.

Nos anos 1990, houve um período nulo de produção habitacional, devido a um momento político nacional instável e uma política neoliberal de corte de investimento. $\mathrm{O}$ investimento em habitações sociais só voltou nos anos 2000 com o PMCMV, quando tivemos a produção habitacional de 3.464 habitações sociais espacializadas em 5 conjuntos habitacionais (Santos, 2016).
A tabela 2 representa um contexto de escala nacional - local como forma de compreender como as políticas habitacionais em Presidente Prudente/SP possuem influências verticalizadas.

Pela tabela 2, é possível observar que a política habitacional em Presidente Prudente/SP possui forte influência das relações verticalizadas oriundas do governo federal, inclusive no que se refere ao momento político, conforme destacamos nos anos de 1990.

Ainda observando a tabela 2, pode-se verificar que somente com a atuação do governo federal nos anos 2000 é que teremos uma atuação com relação à produção habitacional e sua institucionalização, mediante a regulamentação do Estatuto da cidade, com a promulgação da Lei n-10.257 de julho de 2001, e da criação do Ministério das Cidades (MCid), no ano de 2003.

Para compreender a importância que as políticas habitacionais possuem na produção do espaço urbano de Presidente Prudente/SP, temos a figura 2 que ilustra essa espacialização dos conjuntos habitacionais tanto do BNH quanto do PMCMV.

Podemos verificar que há uma produção habitacional voltada para a parte mais periférica de Presidente Prudente/ SP tanto na época do BNH, quanto no período de atuação do PMCMV, quando se verifica a intencionalidade de manter esses conjuntos mais populares distantes do centro principal da cidade.

Essas reflexões somente são possíveis quando realizamos uma análise crítica a partir da observação no espaço-tempo da produção habitacional em Presidente Prudente/SP. Tal visão só é permitida quando nos utilizamos da objetividade 
Tabla 2

Relação de fatos históricos nível nacional- local: a relação com a política habitacional brasileira. (1920 - 2000).

\begin{tabular}{|c|c|c|c|c|c|c|c|c|}
\hline & $1920 / 1930$ & 1940 & 1950 & 1960 & 1970 & 1980 & 1990 & ANOS 2000 \\
\hline 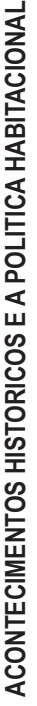 & $\begin{array}{l}1927 \text { - Plano } \\
\text { Agache - } \\
\text { programa de } \\
\text { remodelação da } \\
\text { cidade do Rio de } \\
\text { Janeiro; extinção } \\
\text { das favelas. } \\
1930 \text { - IV } \\
\text { Congresso } \\
\text { Pan-Americano: } \\
\text { A Solução } \\
\text { Econômica } \\
\text { do Problema } \\
\text { Residencial. } \\
1930 \text { - Criação } \\
\text { das Carteiras } \\
\text { Imobiliárias } \\
\text { das Caixas de } \\
\text { Aposentadoria e } \\
\text { Pensões (Lei Eloi } \\
\text { Chaves). } \\
1933 \text { - Criação } \\
\text { dos Institutos de } \\
\text { Aposentadoria e } \\
\text { Pensão (IAP'S); }\end{array}$ & $\begin{array}{l}1940 \text { - No dia } 1^{\circ} \\
\text { de Maio (dia do } \\
\text { trabalho) temos a } \\
\text { implementação do } \\
\text { Salário Mínimo por } \\
\text { região no Brasil; } \\
1946 \text { - Lei } \\
\text { № } 9.218 \text { de } \\
\text { 01/05/1946 - } \\
\text { Fundação Casa } \\
\text { Popular (FCP). } \\
\text { Ampliação de suas } \\
\text { atribuições com } \\
\text { o Decreto Lei No } \\
\text { 9.777. }\end{array}$ & $\begin{array}{l}1950 \text { - Getúlio } \\
\text { Vargas volta ao } \\
\text { poder em } 01 \\
\text { de janeiro após } \\
\text { eleições diretas; } \\
1952 \text { - } 28 \text { casas } \\
\text { são construídas } \\
\text { pela FCP em } \\
\text { âmbito nacional. } \\
1953 \text { - Criação da } \\
\text { PETROBRÁS. } \\
1954 \text { - Vargas é } \\
\text { encontrado morto } \\
\text { em seu gabinete; }\end{array}$ & $\begin{array}{l}1964 \text { - Golpe } \\
\text { Militar de } 31 \text { de } \\
\text { Março depõe } \\
\text { o presidente } \\
\text { João Goulart } \\
\text { que é exilado no } \\
\text { Uruguai; } \\
1964 \text { - Lei No } \\
4.380 \text { 08/1964 - } \\
\text { Banco Nacional } \\
\text { de Habitação } \\
\text { (BNH), Sistema } \\
\text { Financeiro de } \\
\text { Habitação (SFH); } \\
\text { Serviço Federal } \\
\text { de Habitação } \\
\text { e Urbanismo } \\
\text { (SERFHAU); } \\
\text { 1966 - Lei ñ } 5.107 \\
\text { 09/1966 do Fundo } \\
\text { de Garantia por } \\
\text { Tempo de Serviço } \\
\text { (FGTS); }\end{array}$ & $\begin{array}{l}\text { Meados de } 1970 \text { - } \\
\text { Preocupação com } \\
\text { o Planejamento } \\
\text { Urbano; } \\
1975 \text { - Após } \\
\text { concentrar suas } \\
\text { atividades na } \\
\text { classe média, } \\
\text { o BNH cria } \\
\text { programa para } \\
\text { famílias de baixa } \\
\text { renda (PROJETO } \\
\text { CURA, PROJETO } \\
\text { JOÃO DE BARRO, } \\
\text { PROMORAR). } \\
\text { 1979 - Programas } \\
\text { de Saneamento } \\
\text { são criados } \\
\text { (PLANHAP, } \\
\text { PROFILURB E } \\
\text { FICAM). }\end{array}$ & $\begin{array}{l}1984 \text { - Extinção do } \\
\text { Banco Nacional de } \\
\text { Habitação (BNH) } \\
\text { pelo Decreto Lei } \\
\text { № 2.291/86; } \\
\text { 1985 - Eleições } \\
\text { democráticas; } \\
\text { José Sarney } \\
\text { assume. } \\
1985 \text { - Dissolução } \\
\text { do Banco Nacional } \\
\text { de Habitação } \\
\text { (BNH); } \\
\text { 1986 - Formação } \\
\text { de secretarias e } \\
\text { ministérios com } \\
\text { resquícios do } \\
\text { BNH; } \\
\text { 1986 - Criação da } \\
\text { Caixa Econômica } \\
\text { Federal (CEF); }\end{array}$ & $\begin{array}{l}1990 \text { - Eleição de } \\
\text { Collor - Início do } \\
\text { período Neoliberal } \\
\text { no Brasil; } \\
1991 \text { - } \\
\text { Impeachment de } \\
\text { Collor } \\
1992 \text { - Itamar } \\
\text { Franco assume } \\
\text { (Habitar Brasil e } \\
\text { Morar Município); } \\
\text { 1995 - FHC é } \\
\text { eleito; Plano } \\
\text { Real (R\$); (Pró - } \\
\text { Moradia, Habitar } \\
\text { Brasil, Carta de } \\
\text { Crédito). }\end{array}$ & $\begin{array}{l}2001 \text { - Lei N }{ }^{\circ} \\
10.257 \text { de } 10 \text { de } \\
\text { Julho de } 2001 \\
\text { instaura o Estatuto } \\
\text { da Cidade; } \\
\text { 2002 - Luis } \\
\text { Inácio Lula da } \\
\text { Silva assume a } \\
\text { Presidência da } \\
\text { República; } \\
\text { 2009 - Medida } \\
\text { Provisória N }{ }^{\circ} 459 \\
\text { de 25/03/2009 } \\
\text { - Implantava o } \\
\text { Programa Minha } \\
\text { Casa, Minha Vida } \\
\text { (PMCMV). }\end{array}$ \\
\hline 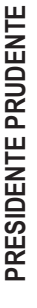 & $\begin{array}{l}1930 \text { - Forte } \\
\text { Intervenção } \\
\text { política a níveis } \\
\text { estadual e federal. }\end{array}$ & $\begin{array}{l}1940 \text { - } \\
\text { Crescimento dos } \\
\text { estabelecimentos } \\
\text { de cunho } \\
\text { industrial. Cerca } \\
\text { de } 138 \text { na cidade. }\end{array}$ & $\begin{array}{l}1950 \text { - Valorização } \\
\text { dos lotes } \\
\text { urbanizados. } \\
\text { Primeiras ações } \\
\text { de incorporadores. }\end{array}$ & $\begin{array}{l}1968 \text { - Jardim } \\
\text { Bongiovani atrai } \\
\text { a atenção de } \\
\text { incorporadores, } \\
\text { pelos inúmeros } \\
\text { serviços } \\
\text { disponíveis e pela } \\
\text { valorização de } \\
\text { seus lotes. }\end{array}$ & $\begin{array}{l}1978 \text { - Implantação } \\
\text { do conjunto } \\
\text { habitacional } \\
\text { Bartholomeu } \\
\text { Bueno de Miranda } \\
\text { (COHAB) com } \\
1025 \text { unidades; }\end{array}$ & $\begin{array}{l}1989 \text { - } \\
\text { Implantação do } \\
\text { Programa de } \\
\text { Desfavelamento } \\
\text { e Lotes } \\
\text { Urbanizados. } \\
\text { (Descentraliza as } \\
\text { ações das políticas } \\
\text { habitacionais } \\
\text { e reforça a } \\
\text { periferização). }\end{array}$ & $\begin{array}{l}1993 \text { - Uso da } \\
\text { Concessão do } \\
\text { Direito Real do } \\
\text { Uso. (Reforça o } \\
\text { sentimento de } \\
\text { segregação das } \\
\text { famílias de baixa } \\
\text { renda) }\end{array}$ & $\begin{array}{l}2013 \text { - Entrega } \\
\text { do conjunto } \\
\text { habitacional } \\
\text { Residencial } \\
\text { Tapajós com cerca } \\
\text { de } 227 \text { habitações. } \\
2014 \text { / } 2015 \text { - Mais } \\
3.418 \text { habitações } \\
\text { entregues. }\end{array}$ \\
\hline
\end{tabular}

Fonte: Santos (2016).

da análise escalar que, conforme já destacamos, possui o caráter político intrínseco no seu debate, qualificando ainda mais as reflexões realizadas.

Desse modo, a análise no espaço-tempo das políticas públicas surge como ponto crítico de tais modelos, onde podemos apontar suas qualidades e seus defeitos diante da sua efetivação desses no espaço. A reflexão por via da escala só vem a contribuir com uma maior efetividade do debate, já que demanda de uma ampla observação de todo o contexto, nesse caso da produção habitacional, mas que também pode ser pensada para outras frentes de análise.

\section{Considerações finais}

As escalas possuem grande influência nas pesquisas voltadas para a Geografia, já que essa ciência tem um caráter de poder dialogar com várias frentes devido à multivariedade de suas informações, que permitem um debate amplo e com qualidade.

Mesmo com vários tipos de escalas, conforme já debatemos, consideramos a necessidade de destacar as geográficas como fator necessário para o entendimento das relações sociais e políticas.

Elas se tornam ainda mais fundamentais ao estudo, devido ao sistema capitalista que possui uma contradição nas suas ações em prol da rentabilidade de seus negócios, tornando o espaço modificado e o tempo fluido.

Quanto mais o capitalismo se efetiva como modelo econômico mundial, mais temos visto a intensa alteração que tem causado nas relações sociais, por exemplo, já que aproxima as pessoas, com a tecnologia e em um tempo reduzido, mas somente realiza isso com aquelas que possuem condições financeiras para tal, tornando-se seletiva e excludente. 


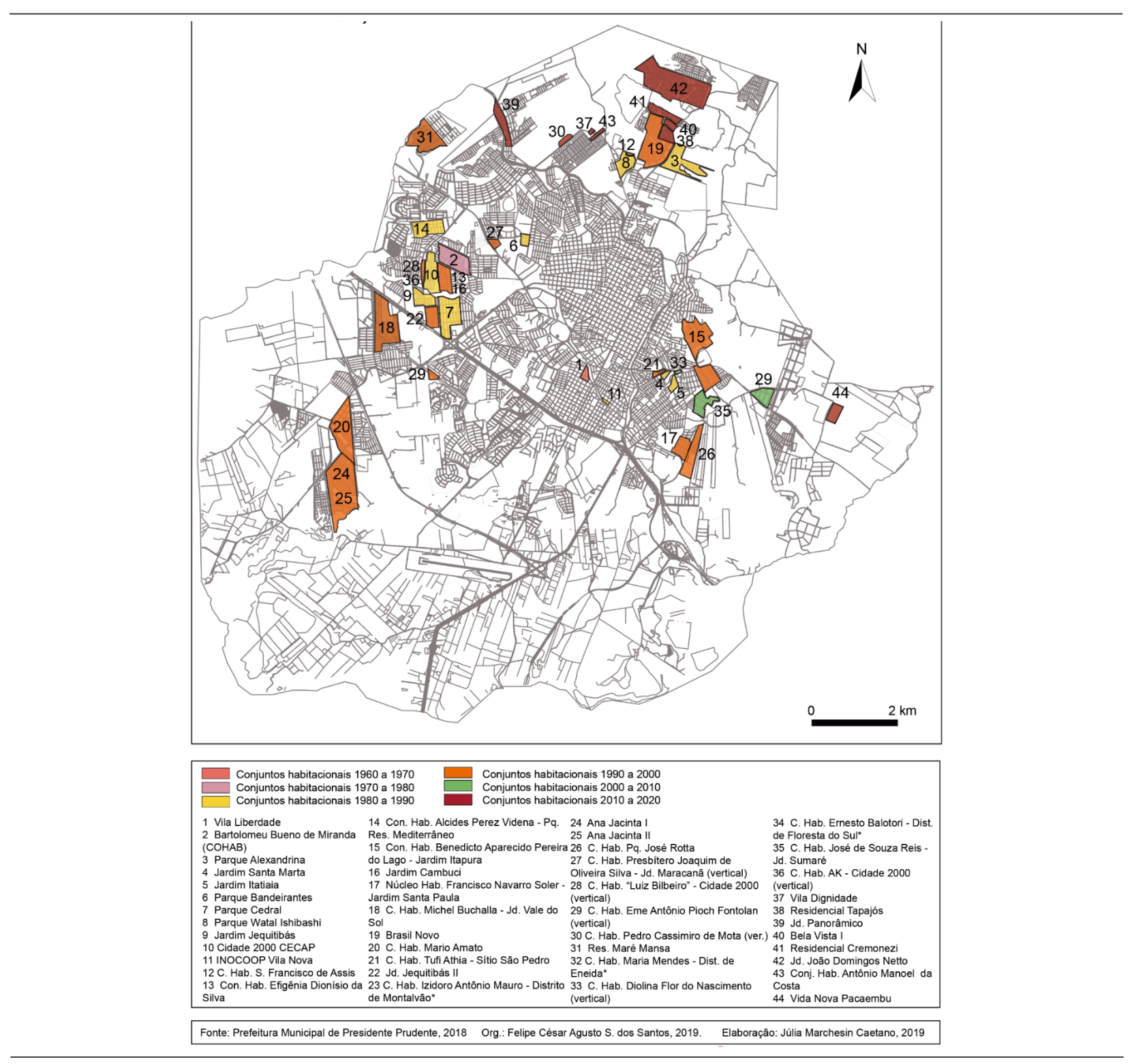

Figura 2. Conjuntos habitacionais em Presidente Prudente (1960 - 2020). Fonte: Santos (2019).

E, se nas relações o sistema capitalista atua de forma a contribuir para esses abismos segregacionistas, na questão política não haveria de ser diferente. Ao pensar na atuação dos governos nacionais em seus países, temos que refletir sobre a influência que as decisões vindas verticalmente poderão suscitar na dinâmica diária da população.

Não é tarefa fácil realizar uma reflexão referente a uma expansão urbana das cidades médias brasileiras, principalmente no que se refere as problemáticas que são originadas por essas novas formas de compreender a cidade.
Ao utilizarmos o exemplo da implantação de uma política pública de cunho habitacional em uma cidade média, demonstramos como a influência dela pode configurar um espaço urbano inteiro, produzindo-o mesmo que de forma a manter as relações de distanciamento entre centro - periferia, oriundo das várias relações criadas entre os poderes políticos e sociais dessa cidade média.

Realizando uma análise mais ampla, não deixando de enfocar a cidade média, podemos traçar algumas ações que tiveram impacto direto em sua dinâmica, como um projeto neoliberal nos anos 1990, que teve influência na questão habitacional, ou até mesmo a criação de um 
Ministério que atuaria coordenando a implantação de uma política habitacional de cunho nacional, como o PMCMV.

Tais reflexões só vêm corroborar com a importância que a análise escalar possui, quando se trata da dinâmica espaço-tempo, não só no âmbito urbano, quanto nas relações agrárias, de clima, na arquitetura e urbanismo etc. Logo, destacamos que ainda há um longo caminho para percorrer no que se refere ao debate das escalas geográficas na Geografia brasileira, ainda mais no tocante à análise espaço-temporal.

Desse modo, nossas análises servem como um caminho para que novos debates sejam apontados e que possamos conduzilos usando do texto exposto, no qual compreendemos que, as escalas geográficas possuem fundamental importância com relação ao entendimento do mundo atual, devido ao seu caráter de análise hierárquica, ainda mais com o diálogo estabelecido com a reflexão no espaço-tempo.

\section{Referências}

Amore, C.S. (2015). "Minha Casa, Minha Vida" para iniciantes. In C.S. Amore, L.Z., Shimbo, M.B.C., Rufino, Minha casa... e a cidade? avaliação do programa minha casa minha vida em seis estados brasileiros (pp. 13-27). Letra Capital.

Bernardini, S. P. (2018). O planejamento da expansão urbana na interface com a urbanização dispersa: uma análise sobre a região metropolitana de Campinas (1970-2006). urbe. Revista Brasileira de Gestão Urbana, 10(1), 172-185. https://doi. org/10.1590/2175-3369.010.001.AO02

Brenner, N. (2013). Reestruturação, reescalonamento e a questão urbana. GEOUSP, 17(1), 198-220. https://doi. org/10.11606/issn.2179-0892.geousp.2013.74311

Carlos, Ana Fani Alessandri. (2009). Da "Geografia Abstrata" a "Geografia Concreta". In F. Mendonça, C.L. Lowen-Sahr \& M. da Silva, Espaço e Tempo: Complexidade e desafios do pensar e do fazer geográfico (pp. 73-90). Ademadan.

Cristianini, M. C. (2020). População com acesso à Internet (2017 - 2019). https://www.jornaljoca. com.br/iniciativas-levam-internet-a-estudantessem-acesso-a-rede/captura-de-tela-2020-10-30as-08-59-31/
Encinas, F., Truffello, R., Aguirre, C., \& Hidalgo, R. (2019). Especulación, renta de suelo y ciudad neoliberal. O por qué con el libre mercado no basta. ARQ (Santiago), 102, 120-133. http://dx.doi. org/10.4067/S0717-69962019000200120

Elias, N. (1998). Sobre o tempo (1ra ed.). Ed. Rio de Janeiro: Jorge Zahar Editor.

Guimarães, R.B. (2003). Atores políticos, representação social e produção da escala geográfica. In J. Gonçalves Melo, Espiral do Espaço (pp. 7-21). FCT UNESP/ GASPERR.

Harvey, D. (1992). A experiência do espaço e do tempo. In D. Harvey, Condição pós-moderna (pp. 185-276). Editora Loyola.

Jimenez, V., Hidalgo, R., Campesino, A. J., \& Alvarado, V. (2018). Normalización del modelo neoliberal de expansión residencial más allá del límite urbano en Chile y España. EURE (Santiago), 44(132), 27-46.http://dx.doi.org/10.4067/s 0250 71612018000200027

Lima, S. M. S. A., Lopes, W. Gomes Reis \& Façanha, A. C. (2019). Desafios do planejamento urbano na expansão das cidades: entre planos e realidade. urbe. Revista Brasileira de Gestão Urbana, 11, e20190037. https://doi.org/10.1590/2175-3369.011.e20180037

Melo, J. Gonçalves. (2003). Geografia, História e a teoria das escalas geográficas. In J. Gonçalves Melo, Espiral do Espaço (pp. 23-40). FCT UNESP/ GASPERR.

Santos, E. de O. \& Silva, F. A. Carneiro da. (2014). Revisitando o conceito de escala na Geografia. Boletim Geográfico, 32(3), 16- 27.

Santos F.C.A. Silgueiro. (2016). Espaço, Tempo e Contradições: Do Banco Nacional de Habitação ao Programa "Minha Casa, Minha Vida" em Presidente Prudente/SP. 124 f. Monografia (Trabalho de Conclusão de Curso em Geografia). Faculdade de Ciências e Tecnologia Universidade Estadual Paulista (UNESP) - Presidente Prudente - SP. 
Santos, F.C.A. Silgueiro. (2019). O espaço-tempo das politicas habitacionais em Presidente Prudentel SP. 164 f. Dissertação (Mestrado em Geografia) Faculdade de Ciências e Tecnologia Universidade Estadual Paulista (UNESP) - Presidente Prudente SP.

Smith, N. (2000). Contornos de uma política espacializada: veículos dos sem teto e produção da escala geográfica. In A. Arantes, $O$ espaço da diferença (pp. 133-175). Papirus.

\section{Agradecimentos}

Agradeço ao Conselho Nacional de Desenvolvimento Científico e Tecnológico que financiou esta pesquisa (133697/2017-7). 